The Nose, Paranasal Sinuses, and Ears in Childhood. By Donald F. Proctor. (Pp. xii $+187 ; 81$ figures. $\$ 12.50$.) Springfield, Illinois: Charles C. Thomas. 1963.

This book is the second of a series of three volumes on paediatric otorhinolaryngology in the series entitled Pediatric Surgical Monographs, all edited by Dr. Mark M. Ravitch. In this volume Dr. Donald Proctor (Associate Professor of Laryngology and Otology at Johns Hopkins University School of Medicine) is concerned with diseases of the nose, paranasal sinuses and ears in childhood.

Chapters are devoted respectively to historical background, physiology, examination technique, diseases of nose, nasal sinuses and ears; and a final chapter on hearing and speech as they affect communication.

In a book of less than 200 pages some subjects cannot be fully discussed. The aim of the book is to refer to and, it is hoped, to clarify a great many controversial issues that concern paediatricians and otorhinolaryngologists. The book is most readable and is punctuated by numerous case reports. The approach is essentially clinical and practical.

The author is concerned with the avoidance of psychological trauma connected with anaesthesia and ear, nose and throat operations, and he gives practical suggestions on these problems. Much space is given to prevention of deafness but more could have been written about the management of congenital deafness and the importance of early diagnosis in the first year of life, with the modern emphasis on training defective hearing as opposed to former methods of training, when the emphasis was on lip-reading and signing. The volume is well produced and, as in all the books in this series, the illustrations and photographs are of a high quality. There is a good bibliography, mostly of American references; the index is adequate.

This book will appeal mainly to young otorhinolaryngologists and paediatricians to whom it will give much sound practical advice.

\section{Proceedings of the Second International Congress on Mental Retardation, Wien, 14-19 August, 1961.}

Part I: Organic Bases and Biochemical Aspects of Imbecility. Part II: Psychological and Sociological Problems in Imbecility. Drug Treatment. Edited by Otto Stur. (Part I: Pp. viii $+416 ; 174$ figures + 86 tables. S.Fr./DM. 70.-; Part II: Pp. viii + 261 ; 13 figures +30 tables. S.Fr./DM. 50.-; Parts I and II together, S.Fr./DM. 100.-.) Basel and New York: S. Karger. 1963.

These volumes are a record of the Proceedings of the Second International Congress on Mental Retardation which took place in Vienna in August 1961. They contain more than a hundred papers in French, German and English, which are concerned with many different aspects of mental retardation. There is some overlap between the volumes and some readers may be surprised to find a paper on 'Les troubles du développement intellectuel chez l'enfant épileptique' by Dongier and Gastaut in Volume 1. Some of the papers presented are almost philosophical in outlook, for example those of Gröer and Frontali in Volume 2. Other papers consist essentially of surveys of current knowledge of particular aspects of mental retardation, for example the papers by Gross and Seitelberger on the structural brain abnormalities underlying mental retardation and that by Cumings on the Cerebral Lipids and Mental Retardation, and a quite outstanding article by Norman on the Neuropathological Aspects of the Lipidoses and the Leucodystrophies. Other papers are more limited in scope and present the results of recent research in various aspects of mental deficiency. For example, there are three papers on the metabolic disorders found in phenylketonuria, a number of papers describing collections of odd clinical findings, some of which amount to syndromes and some of which do not, and others which describe research into the causes of the psychological aspects of mental retardation.

Inevitably, the papers vary widely in quality. The papers on mongolism are rather disappointing, but it is unlikely that anybody interested in mental retardation could read these volumes without finding something new and exciting in at least some of the papers presented. On the other hand, the conference seems to have touched on many subjects and dealt exhaustively with none of them. Perhaps this is inevitable with conferences as large as this one, but one is bound to ask the question whether a smaller conference devoted to a particular aspect of mental retardation might not have been more productive.

These books are beautifully printed on good paper, and misprints are surprisingly few for a trilingual publication. Inevitably they are rather expensive.

Differentialdiagnose seltener Lungenerkrankungen im Röntgenbild. Ein Atlas. Edited by KARL MUSSHOFF and Jürgen WeInREICH. (Pp. viii $+205 ; 112$ figures. DM. 108.) Berlin: Springer. 1962.

This is a radiological atlas, illustrating some of the rarer forms of lung disease. After short sections of text on the technique of chest radiography and general aspects of radiological interpretation, subsections deal with different types of pulmonary opacities. The differential diagnosis of widespread opacities, multiple patchy lesions, solitary rounded, striated and hilar opacities and translucent lesions are discussed separately. Each subsection is followed by a considerable number of illustrative case histories with the corresponding radiographs.

Much of the case material is beyond the paediatric age-group, but there is a fair representation of children. The illustrations are good (although reproduced in the positive sense). It is an interesting book through which to glance, perhaps of more value to the radiologist than to the paediatrician. 